\title{
Probiotics as a Weapon in the Fight Against COVID-19
}

\author{
Elisavet Stavropoulou ${ }^{1,2,3 *}$ and Eugenia Bezirtzoglou ${ }^{4}$ \\ ${ }^{1}$ Department of Medicine, Centre Hospitalier Universitaire Vaudois (CHUV), Lausanne, Switzerland, ${ }^{2}$ Service of Infectious \\ Diseases, Central Institute of Valais Hospitals, Sion, Switzerland, ${ }^{3}$ Department of Medicine, Lausanne University Hospital and \\ University of Lausanne, Lausanne, Switzerland, ${ }^{4}$ Laboratory of Hygiene and Environmental Protection, Medical School, \\ Democritus University of Thrace, Alexandroupolis, Greece
}

Keywords: COVID-19, probiotics, immunology, coronaviruses (CoV), vanA, adjuvant, therapy, protein E

OPEN ACCESS

Edited by:

Zhaojun Wei,

Hefei University of Technology, China

Reviewed by:

Kiran Thakur,

Hefei University of Technology, China

*Correspondence:

Elisavet Stavropoulou elisabeth.stavropoulou@gmail.com

Specialty section:

This article was submitted to Nutrition and Food Science Technology,

a section of the journal Frontiers in Nutrition

Received: 07 October 2020 Accepted: 24 November 2020 Published: 15 December 2020

Citation: Stavropoulou E and Bezirtzoglou E (2020) Probiotics as a Weapon in the

Fight Against COVID-19.

Front. Nutr. 7:614986.

doi: 10.3389/fnut.2020.614986
In our previously published work, we support that probiotics could be used as an adjunctive treatment against COVID-19 (1) and other colleagues have also focused their attention on this subject $(2,3)$.

Probiotics boost the immune system, enhance the mucosal barrier function and inhibit bacterial adherence and invasion capacity in the intestinal epithelium by being in a direct antagonism with pathogenic bacteria (1). The gut-lung axis is involved in the pathogenicity of bacterial and viral infections, as the intestinal microbiota boosts the alveolar macrophage activity, thus having a protective role in host defense against pneumonia (1). Along these lines, current clinical evidence connects gut, lung, and brain as an entity with communication mediated through complex neural, immunologic inflammatory, and neuroendocrine networks, the so called gut-brain-lung axis (4). There are indications in animals and humans that intestinal microbiota provides bacteria to the lungs, as abundance of Bacteroides sp. is observed in the lung following sepsis (5). Moreover, following sepsis, neurologic and cognitive outcomes are observed $(4,6)$. Without any doubt, the importance of the gut microbiome is stated (1). The composition of the gut microbiome may be used as a predictive tool of disease development and infection severity $(1,7,8)$.

Pattern recognition receptors (PRRs) are of major importance for the developing of the innate immune response (9). Probiotics regulate the innate immune cells via interactions between cell wall components or metabolites with host PRRs (10). Yet, probiotic bacteria are activating Dendritic Cells (DCs) and macrophages boosting adaptive immune responses (B cell differentiation, $\mathrm{T}$ cell homing, Th17 cell stimulation) (11). The expression of Pattern Recognition Receptors (PRRs) is inflamed in the lung cells during inflammation processes. In this context, macrophages, monocytes and neutrophils are responding by increasing levels of PAMPs (Pathogen-Associated Molecular patterns) and DAMPs (Danger-Associated Molecular Patterns) (12).

Besides that, the PRRs recognize DAMPs (Danger-Associated Molecular Patterns) as danger signals emitted by damaged or necrotic host cells which stimulate the pro-inflammatory response (6). Intruder's viral pathogens show a distinctive particular image of PAMPs giving a specific immune response (9). PAMPs are nucleic acids or glycoproteins indispensable for the pathogens' survival. PAMPs should be identified by PRRs leading to the expression of co-stimulatory molecules such as cytokines and chemokines which, in their turn, should activate the antigen presenting cells and specific adaptive immunity by eliminating pathogens $(6,13)$. It is of note that the most studied PRRs for pathogens' recognition are TLRs (Toll Like Receptors) which are membrane glycoproteins (12). The expression of Pattern Recognition Receptors (PRRs) is inflamed in the lung cells during inflammation processes. TLR4 signaling in pulmonary stromal cells is critical for inflammation in the airways and probiotics reduce inflammation by limiting the expression of TLR4 (11).

SARS-CoV-2 belongs to the Coronaviridae which is a family of enveloped, positive-sense, singlestranded RNA (+ssRNA) viruses $(14,15)$. SARS-CoVs possess 3 main structural proteins in the virion envelope $(15,16)$ : (a) protein $S$ (Spike) which permits adherence and fusion, (b) protein $M$ (Membrane) being the most abundant in the virus envelope and participating in the virion assembly 
together with protein E, and finally (c) protein E (envelope) which is the less abundant protein in the virion envelope possessing a single hydrophobic domain (HD) (16). In addition, SARS-CoV-2 contains the nucleocapsid protein (N) (14).

It is believed that SARS-CoV E protein assembles into a homopentamer (15). Furtherly, SARS-CoV E can oligomerize and form a channel. Particularly, SARS-CoV E proteins create cation-selective ion channels, forming a viroporin $(17,18)$. It is a proteolipidic pore with negatively charged planar lipids in bilayers which amplify ion conductance and cation selectivity (19).

It is reported that viral ion channels (viroporins) instigate a leakage in host cellular membranes influencing the membrane role (19). Thus, viroporins set out a role of markers of a viral infection (20). Coronaviruses usually possess three types of ion channels: E, 8a and 3a (21). The 3a ion channel has 3 TMD (Trans-Membrane Domain), while the $\mathrm{E}$ and $8 \mathrm{a}$ ion channels have one TMD (21). Yet, $3 \mathrm{a}$ and protein $\mathrm{E}$ were found to possess a common structural aminoacid PDZ domain-Binding Motif (PBM) which is known to play a key role in anchoring receptor proteins in the membrane $(22,23)$. There is evidence that the last four aminoacids in the C-terminus $\mathrm{PBM}$ of the E protein are actively participating in the development of SARS-CoV disease resulting in the overexpression of cytokines, called the "cytokine storm" (23).

There has been some evidence that protein $\mathrm{E}$ is profusely expressed in the infected cell as it is found mainly in ERGIC (Endoplasmic Reticulum-Golgi Intermediate Compartment), while only a small protein fragment is found in the envelope of the virion (24-26).

It should be reported that the PBM is found only in several coronaviruses, specifically in the genera $\alpha$ and $\beta$, while it is not present in the $\gamma$ genera (24). Without any doubt, it should be interesting to investigate the role of the interaction patterns and whether they interact specifically with the protein E of SARS-CoV or also with protein $\mathrm{E}$ from other coronavirus species of the same genus (27).

Moreover, in coronaviruses, the ERGIC intercedes in between the endoplasmic reticulum and the Golgi for dispensing the virions from the infected cell (26) and accommodates $\mathrm{Ca} 2+$ transport (28). As a result, activation of the NLRP3 inflammasome occurs going along with an overproduction of interleukin $1 \beta$ (29). E protein found in the ERGIC participates in the formation of the infectious virion SARS-CoV E protein involves a triple role; viral assembly, virion release, and viral pathogenesis $(28,29)$. SARS-Cov E protein has been mentioned to connect to five host proteins (Bcl-xL, PALS1, syntenin, sodium/potassium $(\mathrm{Na}+/ \mathrm{K}+)$ ATPase $\alpha-1$ subunit, and stomatin) (24) in SARS-1, permitting virus replication in the host.

Studies have shown that administration of a p38 MAPK inhibitor boosted the survival rate in mice following SARS$\mathrm{CoV}$ infection (30) defining its importance in SARS-CoV virulence. Thus, the PBM virulent domain of $\mathrm{E}$ protein activates the immunopathological mechanisms by using syntenin as a mediator of p38 MAPK induced inflammation (31).

Lactobacillus contains a HSP27-inducible polyphosphate (poly P) fraction. Probiotic-derived polyphosphates, strengthen the epithelial barrier function and keep intestinal homeostasis through the integrin-p38 MAPK pathway (32).

The importance of protein $\mathrm{E}$ in the pathogenesis of mutant SARS-CoV viruses is stated $(18,19)$ as mutant of SARS-CoV with inactive E protein in experimental mice model and in vitro cell culture able to retrograde protein $\mathrm{E}$ in its initial active status (24). Further to the above, the absence of protein $\mathrm{E}$ viroporin is related to shrinking of pulmonary edema as well as to lower mortality rates in mice (33). In this vein, other authors observed the absence of protein $\mathrm{E}$ to be related to inefficient viral maturation, incompetent progenitors and reduced viral levels (34). Minor PBM mutations of protein E seems to be bearable while PBM main domain remains intact (24). In this regard, knowledge on PBM mutants and their interaction capacity with host cell proteins will provide us information on the virus pathogenicity.

It is known that SARS-CoV protein $\mathrm{M}$ is participating also in the viral envelope assembly and release of the virions (35) but in spite of that there is no evidence of protein $\mathrm{M}$ role in membrane morphology (35). Membrane deviating morphology seems to be exclusively related to the protein E in SARS-CoV (35).

Moreover, analysis of viral proteins by VaxiJen software in order to test the probability of antigenic proteins showed evidence that protein $\mathrm{E}$ was the most antigenic (36).

Here we report the Avian infectious bronchitis virus (IBV) which prerequisites grounds in the hydrophobic domain (HD) of protein E (17). There is biochemical evidence of 2 different oligomeric forms of protein $\mathrm{E}$ in IBV; the one is involved in the IBV assembly and the other form participates in the disarray of the secretory pathway (17). It is then expected that broader knowledge of the SARS-CoV protein E will supply us with novel therapeutic targets (37).

Successfully, antiviral drugs that target viroporins were designed (36). Antiviral drugs either inhibit proton conduction in the channel and directly block the channel passage or bind to six sites located outside the channel cavity and inhibit cation conduction with an allosteric mechanism (38). In this context, amantadine and rimantadine were proposed for the treatment of influenza viruses (39).

As stated previously, evidence of additional interaction partners for SARS-CoV E protein could offer a real targeted therapeutic option for the disease treatment (24). Probiotics interact with protein $\mathrm{E}$ and result in the internalization of the virion stimulating macrophages, dendritic and mast cells thus, releasing cytokines and chemokines (24) and stimulating the host immunity (40).

Despite the meaningful research progress on viroporins' structure and on the role of SARS-CoV protein $\mathrm{E}$ in viral replication, such as assembly, membrane functioning, virion release, inflammation, autophagy and apoptosis, major challenges lie ahead in research in order to get knowledge on the implicated physio-pathological mechanisms and settle therapeutic approaches for the treatment of COVID-19. Medications deactivating the enzymes implicated in these mechanisms should be hopeful as potential antiviral treatments.

Current research is focused on the use of probiotics as a carrier of exogenous antigens into the mucosa, where they can boost IgA production and develop an enhanced $\mathrm{T}$ cell response 
(41-43). In this vein, Lactobacillus sp. were used to release influenza H9N2 hemagglutinin or even H1N1 M2e protein as an approach to enhance the influenza virus vaccine efficacy (42-44). Another study reported that oral administration of probiotics can differentially affect gene expression, and may boost the antiviral activity $(45,46)$.

All the above, suggest the potential effect of probiotics as a potential therapeutic approach for COVID-19.

Nevertheless, probiotics should be used with caution, especially in critically ill patients (1). They are not recommended in immunocompromised patients or those with prosthetic valves due to their potential of invasive infections (1). Moreover, some of them have been incriminated as potential recipients of resistance genes (vanA gene cluster due to E. faecium SF68 strain)

\section{REFERENCES}

1. Stavropoulou E, Bezirtzoglou E. Probiotics in medicine: a long debate. Front Immun. (2020) 11:2192. doi: 10.3389/fimmu.2020.02192

2. Mak JWY, Chan FKL, Ng SC. Probiotics and COVID-19: one size does not fit all. Lancet Gastroenterol Hepatol. (2020) 5:644-45. doi: 10.1016/S2468-1253(20)30122-9

3. Baud D, Dimopoulou Agri V, Gibson GR, Reid G, Gionnoni E. Using probiotics to attend the curve of coronavirus disease COVID-2019 pandemic. Front Pub Health. (2020) 8:186. doi: 10.3389/fpubh.2020. 00186

4. Stevens RD, Puybasset L. The brain-lung-brain axis. Intensive Care Med. (2011) 37:1054-6. doi: 10.1007/s00134-011-2233-1

5. Dickson RP, Singer BH, Newstead MW, Falkowski NR, Erb-Downward JR, Standiford J, et al. Enrichment of the lung microbiome with gut bacteria in sepsis and the acute respiratory distress syndrome. Nat Microbiol. (2016) 1:16113. doi: $10.1038 /$ nmicrobiol.2016.113

6. Wiersinga WJ, Leopold SJ, Cranendonk DR, van der Poll T. Host innate immune responses to sepsis. Virulence. (2014) 5:36-44. doi: 10.4161/viru.25436

7. Hakim h, Dallas R, Wolf J, Tang L, Schultz-Cherry S, Darling V, et al. Gut microbiome composition predicts infection risk during chemotherapy in children with acute lymphoblastic leukemia. Clin Inf Dis. (2018) 67:5418. doi: 10.1093/cid/ciy153

8. Chen CJ, Wu GH, Kuo RL, Shih SR. Role of the intestinal microbiota in the immunomodulation of influenza virus infection. Micr Inf. (2017) 19:5709. doi: 10.1016/j.micinf.2017.09.002

9. Baccala R, Gonzalez-Quintial R, Lawson BR, Theofilopoulos AN. Sensors of the innate immune system: their mode of action. Nat Rev Rheumatol. (2009) 5:448-56. doi: 10.1038/nrrheum.2009.136

10. Mogensen TH. Pathogen recognition and inflammatory signaling in innate immune defenses. Clin Microbiol Rev. (2009) 22:24073. doi: 10.1128/CMR.00046-08

11. Mortaz E, Adcock IM, Folkerts G, Barnes PJ, Vos AP, Garssen J. Probiotics in the management of lung diseases. Mediat Inflamm. (2013) 2013:751068. doi: 10.1155/2013/751068

12. Pedraza ST, Betancur JG. Viral Recognition by the Innate Immune System: The Role of Pattern Recognition Receptors. Available online at: http://colombiamedica.univalle.edu.co/index.php/comedica/article/view/ 731/1195 (accessed May 5, 2020).

13. Steinhagen F, Schmidt SV, Schewe C, Bode C. Immunotherapy in sepsis - brake or accelerate? Pharmacol Ther. (2020) 208:107476. doi: 10.1016/j.pharmthera.2020.107476

14. Choudhury A, Mukherjee S. In silico studies on the comparative characterization of the interactions of SARS-CoV-2 spike glycoprotein with ACE-2 receptor homologs and human TLRs. J Med Virol. (2020) 92:2105-13. doi: 10.1002/jmv.25987
(47). Finally, some have high enzymatic activity, expressing CYP enzymes, specifically P450 that could interfere in drugs' metabolism and bioavailability $(48,49)$.

Yet, a clearer understanding of the implicated mechanisms of action of probiotics, specification of the biochemical profile of the enigmatic SARS protein $\mathrm{E}$ and clinical trials are needed, in order to assign a probiotic as efficient in the prophylaxis or field therapy of COVID-19.

\section{AUTHOR CONTRIBUTIONS}

All authors listed have made a substantial, direct and intellectual contribution to the work, and approved it for publication.

15. de Wit E, van Doremalen N, Falzarano D, Munster VJ. SARS and MERS: recent insights into emerging coronaviruses. Nat Rev Microbiol. (2016) 14:523-34. doi: 10.1038/nrmicro.2016.81

16. Malik YA. Properties of coronavirus and SARS-CoV-2. Malays J Pathol. (2020) 42:3-11.

17. Westerbeck JW, Machamer CE. A coronavirus E protein is present in two distinct pools with different effects on assembly and the secretory pathway. J Virol. (2015) 89:9313-23. doi: 10.1128/JVI.01237-15

18. Wilson L, McKinlay C, Gage P, Ewart G. SARS coronavirus E protein forms cation-selective ion channels. Virology. (2004) 330:322-31. doi: 10.1016/j.virol.2004.09.033

19. Verdia-Baguena C, Nieto-Torres JL, Alcaraz A, DeDiego ML, Torres J, Aguilella VM, et al. Coronavirus E protein forms ion channels with functionally and structurally-involved membrane lipids. Virology. (2012) 432:485-94. doi: 10.1016/j.virol.2012.07.005

20. Farag NS, Breitinger U, Breitinger HG, El Azizi MA. Viroporins and inflammasomes: a key to understand virus-induced inflammation. Int J Biochem Cell Biol. (2020) 122:105738. doi: 10.1016/j.biocel.2020.105738

21. DeDiego ML, Nieto-Torres JL, Jimenez-Guardeño JM, Regla-Nava JA, Castaño-Rodriguez C, Fernandez-Delgado R, et al. Coronavirus virulence genes with main focus on SARS-CoV envelope gene. Virus Res. (2014) 194:124-37. doi: 10.1016/j.virusres.2014.07.024

22. Genera M, Samson D, Raynal B, Haouz A, Baron B, Simenel C, et al. Structural and functional characterization of the PDZ domain of the human phosphatase PTPN3 and its interaction with the human papillomavirus E6 oncoprotein. Sci Rep. (2019) 9:7438. doi: 10.1038/s41598-019-43932-x

23. Jimenez-Guardeño JM, Nieto-Torres JL, DeDiego ML, Regla-Nava JA, Fernandez-Delgado R, Castaño-Rodriguez $C$, et al. The PDZ-binding motif of severe acute respiratory syndrome coronavirus envelope protein is a determinant of viral pathogenesis. PLOS Pathog. (2014) 10:e1004320. doi: 10.1371/journal.ppat. 1004320

24. Schoeman D, Fielding, B.C. Coronavirus envelope protein: current knowledge. Virol J. (2019) 16:69. doi: 10.1186/s12985-019-1182-0

25. Venkatagopalan P, Daskalova SM, Lopez LA, Dolezal KA, Hogue BG. Coronavirus envelope (E) protein remains at the site of assembly. Virology. (2015) 478:75-85. doi: 10.1016/j.virol.2015.02.005

26. Nieto-Torres JL, DeDiego ML, Álvarez E, Jiménez-Guardeño JM, ReglaNava JA, Llorente $M$, et al. Subcellular location and topology of severe acute respiratory syndrome coronavirus envelope protein. Virology. (2011) 415:69-82. doi: 10.1016/j.virol.2011.03.029

27. Wu Q, Zhang Y, Lü H, Wang J, He X, Liu Y, et al. The E protein is a multifunctional membrane protein of SARS-CoV. Geno Prot Bioinform. (2003) 1:131-44. doi: 10.1016/S1672-0229(03)01017-9

28. Klaus JP, Eisenhauer P, Russo J, Mason AB, Do D, King B, et al. The intracellular cargo receptor ERGIC-53 is required for the production of infectious arenavirus, coronavirus, and filovirus particles. Cell Host Microbe. (2013) 14:522-34. doi: 10.1016/j.chom.2013.10.010 
29. Nieto-Torres JL, Verdiá-Báguena C, Jimenez-Guardeño JM, ReglaNava JA, Castaño-Rodriguez C, Fernandez-Delgado R, et al. Severe acute respiratory syndrome coronavirus $\mathrm{E}$ protein transports calcium ions and activates the NLRP3 inflammasome. Virology. (2015) 485:330-9. doi: 10.1016/j.virol.2015.08.010

30. Lau JM, Jin X, Ren J, Avery J, DeBosch BJ, Treskov I, et al. The 14-3-3tau phosphoserine-binding protein is required for cardiomyocyte survival. $\mathrm{Mol}$ Cell Biol. (2007) 27:1455-66. doi: 10.1128/MCB.01369-06

31. Menon R, Papaconstantinou J. p38 Mitogen activated protein kinase (MAPK): a new therapeutic target for reducing the risk of adverse pregnancy outcomes. Expert Opin Ther Targets. (2016) 20:1397-412. doi: 10.1080/14728222.2016.1216980

32. Segawa S, Fujiya M, Konishi H, Ueno N, Kobayashi N, Shigyo T, et al. Probiotic-derived polyphosphate enhances the epithelial barrier function and maintains intestinal homeostasis through integrin-p38 MAPK pathway. PLoS ONE. (2011) 6:e23278. doi: 10.1371/journal.pone.0023278

33. Nieto-Torres JL, DeDiego ML, Verdiá-Báguena C, Jimenez-Guardeño JM, Regla-Nava JA, Fernandez-Delgado R, et al. Severe acute respiratory syndrome coronavirus envelope protein ion channel activity promotes virus fitness and pathogenesis. PLOS Pathog. (2014) 10:e1004077. doi: 10.1371/journal.ppat.1004077

34. Li C, Qi Y, Teng X, Yang Z, Wei P, Zhang C, et al. Maturation mechanism of severe acute respiratory syndrome (SARS) coronavirus 3C-like proteinase. $J$ Biol Chem. (2010) 285:28134-40. doi: 10.1074/jbc.M109.095851

35. Hu Y, Wen J, Tang L, Zhang H, Zhang X, Li Y, et al. The M protein of SARS$\mathrm{CoV}$ : basic structural and immunological properties. Geno Prot Bioinform. (2003) 1:118-30. doi: 10.1016/S1672-0229(03)01016-7

36. Abdelmageed MI, Abdelmoneim AH, Mustafa MI, Elfadol NM, Murshed NS, Shantier SW, et al. Design of a multiepitope-based peptide vaccine against the E protein of human COVID-19: an immunoinformatics approach. BioMed Res Int. (2020) 11:2683286. doi: 10.1101/2020.02.04.934232

37. Börgeling Y, Schmolke M, Viemann D, Nordhoff C, Roth J, Ludwig S. Inhibition of p38 mitogen-activated protein kinase impairs influenza virus-induced primary and secondary host gene responses and protects mice from lethal H5N1 infection. J Biol Chem. (2014) 289:13-27. doi: 10.1074/jbc.M113.469239

38. Yang BO, Chou JJ. The minimalist architectures of viroporins and theirtherapeutic implications. Biochim Biophys Acta. (2014) 1838:105867. doi: 10.1016/j.bbamem.2013.09.004

39. Pinto LH, Holsinger LJ, Lamb RA. Influenza virus M2 protein has ion channel activity. Cell. (1992) 69:517-28. doi: 10.1016/0092-8674(92)90452-I

40. Delcenserie V, Martel D, Lamoureux M, Amiot J, Boutin Y, Roy D. Immunomodulatory effects of probiotics in the intestinal tract. CIMB. (2008) 10:37-54.

41. Mohamadzadeh M, Duong T, Sandwick SJ, Hoover T, Klaenhammer TR. Dendritic cell targeting of Bacillus anthracis protective antigen expressed by Lactobacillus acidophilus protects mice from lethal challenge. Proc Natl Acad Sci USA. (2009) 106 :4331-6. doi: 10.1073/pnas.09000 29106

42. Huyghebaert N, Vermeire A, Neirynck S, Steidler L, Remaut E, Remon JP. Development of an enteric-coated formulation containing freezedried, viable recombinant Lactococcus lactis for the ileal mucosal delivery of human interleukin-10. Eur J Pharm Biopharm. (2005) 60:349-59. doi: 10.1016/j.ejpb.2005.02.012

43. Vandenbroucke K, de Haard H, Beirnaert E, Dreier T, Lauwereys M, Huyck $\mathrm{L}$, et al. Orally administered L. lactis secreting an anti-TNF nanobody demonstrate efficacy in chronic colitis. Mucosal Immunol. (2010) 3:4956. doi: $10.1038 / \mathrm{mi} .2009 .116$

44. Shi SH, Yang WT, Yang GL, Cong YL, Huang HB, Wang Q, et al. Immunoprotection against influenza virus $\mathrm{H} 9 \mathrm{~N} 2$ by the oral administration of recombinant Lactobacillus plantarumNC8 expressing hemagglutinin in BALB/c mice. Virology. (2014) 464-65:166-76. doi: 10.1016/j.virol.2014.07.011

45. Shi SH, Yang WT, Yang GL, Zhang XK, Liu YY, Zhang LJ et al. Lactobacillus plantarum vaccine vector expressing hemagglutinin provides protection against H9N2 challenge infection. Virus Res. (2016) 211:4657. doi: 10.1016/j.virusres.2015.09.005

46. Yang WT, Yang GL, Wang Q, Huang HB, Jiang YL, Shi CW, et al. Protective efficacy of Fc targeting conserved influenza virus M2e antigen expressed by Lactobacillus plantarum. Antivir Res. (2017) 138:9-21. doi: 10.1016/j.antiviral.2016.11.025

47. Lund B, Edlund C. Probiotic Enterococcus faecium strain is a possible recipient of the vanA gene cluster. Clin Infect Dis. (2001) 32:13845. doi: 10.1086/319994

48. Bezirtzoglou E. Intestinal cytochromes $\mathrm{P} 450$ regulating the intestinal microbiota and its probiotic profile. Microb Ecol Health Dis. (2012) 23:10.3402/mehd.v23i0.18370. doi: 10.3402/mehd.v23i0.18370

49. Stavropoulou E, Pircalabioru GG, Bezirtzoglou E. The role of cytochromes P450 in infection. Front Immunol. (2018) 9:89. doi: 10.3389/fimmu.2018.00089

Conflict of Interest: The authors declare that the research was conducted in the absence of any commercial or financial relationships that could be construed as a potential conflict of interest.

Copyright (c) 2020 Stavropoulou and Bezirtzoglou. This is an open-access article distributed under the terms of the Creative Commons Attribution License (CC BY). The use, distribution or reproduction in other forums is permitted, provided the original author(s) and the copyright owner(s) are credited and that the original publication in this journal is cited, in accordance with accepted academic practice. No use, distribution or reproduction is permitted which does not comply with these terms. 